\title{
A double blind randomised trial of low power laser treatment in rheumatoid arthritis
}

\author{
J K Heussler, G Hinchey, E Margiotta, R Quinn, P Butler, J Martin, A D Sturgess
}

\begin{abstract}
Objectives-To define the value of low power laser treatment in small joint rheumatoid arthritis.

Methods-Twenty five women with active disease were recruited. The metacarpophalangeal and proximal interphalangeal joints of one hand were treated with 12 $\mathrm{J} / \mathrm{cm}^{2}$ for $30 \mathrm{~s}$ with a gallium-aluminiumarsenate laser. The other hand received a sham laser treatment designed so that neither therapist nor patient could distinguish the active laser from the sham laser. Each patient received 12 treatments over four weeks. The following parameters were measured: pain as assessed by visual analogue scale; range of joint movements; grip strength; duration of early morning stiffness, joint circumference, Jebsen's hand assessment; drug usage; total swollen joint counts; Arthritis Impact Measurement Scales; three phase bone scans; haematological and serological tests.
\end{abstract}

Results-A total of $72 \%$ of patients reported pain relief but this reduction was reported equally in both hands. No significant changes were seen in other clinical, functional, scintigraphic, or laboratory features. Neither patients nor staff were able to detect which hand was treated with the active laser.

St George Hospital, Sydney,

Australia

Department of

Rheumatology

J K Heussler

A D Sturgess

Department of

Physiotherapy

G Hinchey

E Margiotta

Department of

Nuclear Medicine

R Quinn

P Butler

Department of

Occupational Therapy

J Martin

Correspondence to:

Dr Allan Sturgess,

Department of

Reumatology,

Rheumatology,
Wniversity of New South
Wales,

Wales,

Sydney 2217, Australia.

Accepted for publication 18 March 1993
Conclusion-When this specific laser and dose regimen was used, low power laser treatment had no objective effect on patients with rheumatoid arthritis. It did appear to produce analgesia through a powerful placebo effect.

(Ann Rheum Dis 1993; 52: 703-706)

Low power laser treatment is increasingly used as a modality of physical therapy in the management of a variety of musculoskeletal diseases, including rheumatoid arthritis (RA). ${ }^{111}$ A variety of laser sources are used, such as gallium-aluminium-arsenate, heliumneon, gallium-arsenate, with power outputs of $50 \mathrm{~mW}$ or less. No thermal energy is delivered, and the laser may be within the visible light spectrum or invisible.

In patients with RA, previous workers have reported that laser treatment produces both local and systemic changes, including decreased joint pain, decreased joint swelling, increased functional activity, decreased duration of early morning stiffness, and improved laboratory parameters including erythrocyte sedimentation rate. ${ }^{3}$ No mechanism of action has been defined but photochemical reactions, particularly in the mitochondria, have been suggested. ${ }^{12-13}$ The optimal wavelength and dosage for the treatment of RA is unknown as, depending on the experimental system, either inhibition or stimulation of selected cell functions has been reported. ${ }^{14} \mathrm{~A}$ wide range of differing wavelengths and doses has been used in published reports making it difficult to compare studies (table).

In our hospital, treatment with a galliumaluminium-arsenate laser appeared to produce significant benefit in patients with active RA in the hands. We therefore designed a double blind trial to investigate local changes in the hands of patients with RA, and to document any systemic changes. A protocol employing sham laser treatment to one hand was preferred rather than the use of a non-treatment group, so that each patient had an opportunity to benefit from active treatment, and each patient could compare changes in their two hands.

\section{Patients and methods}

Twenty eight women with RA and bilateral involvement of their metacarpophalangeal and proximal interphalangeal joints were selected from the St George's Hospital rheumatology outpatients department, and by means of a small notice in the local paper. Patients were excluded if they were having an acute inflammatory episode, had arthroplasties in either joint, were pregnant, or had evidence of digital vasculitis. Each patient was randomly allocated to one of two groups. Group 1 received active laser treatment to their right hand, whereas the left hand received sham laser treatment. Group 2 were treated in the reverse manner.

Of the 28 selected, three withdrew from the study: one because of an acute inflammatory episode and social reasons, another for social reasons alone, and the third because of admission to hospital for a non-related illness and surgery. Only the 25 patients who completed the trial were included in the analysis, giving 25 hands treated with active 
Controlled trials of low power laser treatment in rheumatoid arthritis

\begin{tabular}{|c|c|c|c|c|}
\hline Reference & Laser & Design & Evaluation & Effect \\
\hline 2 & $\begin{array}{l}\text { Neodymium } \\
\lambda=1060 \mathrm{~nm} \\
\text { Energy }=15 \mathrm{~J} / \mathrm{cm}^{2} \\
\text { Time }=30 \mathrm{~ns}\end{array}$ & $\begin{array}{l}31 \text { patients, laser to } \\
\text { MCP/PIP of one hand. } \\
\text { Sham laser to other hand. } \\
\text { Once weekly for } 10 \text { weeks }\end{array}$ & $\begin{array}{l}\text { Hand function } \\
\text { Radiology } \\
\text { Haematology }\end{array}$ & Significant \\
\hline 1 & $\begin{array}{l}\text { Helium-neon } \\
\lambda=633 \mathrm{~nm} \\
\text { Energy }=6 \mathrm{~J} / \mathrm{cm}^{2} \\
\text { Power }=10 \mathrm{~mW} \\
\text { Time }=300 \mathrm{~s}\end{array}$ & $\begin{array}{l}17 \text { patients, laser to } 2 \text { nd } \\
\text { MCP of one hand. Sham } \\
\text { laser to } 2 \text { nd MCP of other } \\
\text { hand. Thrice weekly for } 3 \\
\text { weeks }\end{array}$ & $\begin{array}{l}\text { Hand function } \\
\text { Haematology }\end{array}$ & Not significant \\
\hline 3 & $\begin{array}{l}\mathrm{Ga}-\mathrm{Al}-\mathrm{As} \\
\lambda=820 \mathrm{~nm} \\
\text { Energy }=3.5 \mathrm{~J} / \mathrm{cm}^{2} \\
\text { Power }=15 \mathrm{~mW} \\
\text { Time }=60 \mathrm{~s}\end{array}$ & $\begin{array}{l}35 \text { patients, laser to } \\
\text { MCP/PIP of one hand. } \\
\text { Sham laser to control } \\
\text { group. Thrice weekly for } 4 \\
\text { weeks }\end{array}$ & $\begin{array}{l}\text { Hand function } \\
\text { Haematology }\end{array}$ & Significant \\
\hline 22 & $\begin{array}{l}\text { Helium-neon } \\
\lambda=633 \mathrm{~nm} \\
\text { Energy }=3.6 \mathrm{~J} / \mathrm{cm}^{2} \\
\text { Power }=0.5 \mathrm{~mW} \\
\text { Time }=30-480 \mathrm{~s}\end{array}$ & $\begin{array}{l}36 \text { patients, laser to one } \\
\text { group. Sham laser to a } \\
\text { second group. Thrice } \\
\text { weekly for } 10 \text { weeks with } \\
\text { escalating treatment doses }\end{array}$ & Pain (VAS) & Significant \\
\hline
\end{tabular}

$\lambda=$ wavelength; $\mathrm{Ga}-\mathrm{Al}-\mathrm{As}=$ gallium-aluminium-arsenate; $\mathrm{MCP}=$ metacarpophalangeal joint $\mathrm{PIP}=$ proximal interphalangeal joint; VAS=visual analogue scale.

laser and 25 hands treated with sham laser. Al patients were right hand dominant. The two groups were well matched, with group 1 patients having a mean age of 64.8 years (43-77) and a disease duration of $14 \cdot 2$ years (5-30), and group 2 patients having a mean age $62 \cdot 5$ years $(40-80)$ and a disease duration $12 \cdot 7$ years $(5-30)$.

A course of 12 laser treatments was given over a four week period. The active and sham laser probes were identical in external appearance except for a code label, and no visible light, heat, or vibration was detectable from either the active or the placebo probe. The code was kept secret by an uninvolved staff member until all data were analysed.

The treatment was delivered by means of medial and lateral approaches and with the joint held in a loose packed position-that is, $45^{\circ}$ of flexion or neutral position. The treated joints were the metacarpophalangeal, proximal interphalangeal, and the interphalangeal joint of the thumb. A total of $12 \mathrm{~J} / \mathrm{cm}^{2}$ was delivered to each joint via a gallium-aluminium-arsenate laser with the following operating parameters: average power $50 \mathrm{~mW}$; beam spot size $0.126 \mathrm{~cm}^{2}$; pulse width $0.16 \mathrm{~ms}$; pulse frequency $5000 \mathrm{~Hz}$; and wavelength $\lambda 820 \mathrm{~nm}$. The dosage was decided upon empirically after our physiotherapy staff had noted improvements after treatment of patients with this protocol. All treatments were conducted according to the Australian Physiotherapy Association standards, and the techniques and dosages were checked by the St George Hospital Laser Safety Officer. All patients signed an informed consent form and ethical approval was given by the area health service ethics committee.

Weekly measurements were taken, consisting of visual analogue scales used for each hand to assess pain; the duration of early morning stiffness in each hand; joint circumference via a Fröben meter; range of motion for each treated joint via a finger goniometer; grip strength (gross: Jamar hand dynamometer, pinch: pinch gauge, tripod: pinch gauge), index to thumb distance (span) via a goniometer ruler, and the pulp tip to the distal palmar crease distance via a goniometer ruler. In addition, before and after the four week treatment period, the following assessments were done: Jebsen's hand assessment; ${ }^{15}{ }^{16}$ drug usage; total hand swollen joint counts; Arthritis Impact Measurement Scales (AIMS) ${ }^{17}$ three phase bone scans and haematological and serological tests.

Four indices of the AIMS were selected for evaluation: pain; dexterity; activities of daily living; and household activities. In accordance with recommended guidelines, a significant change in the AIMS was said to occur when three out of four indices had demonstrated a change of greater than $30 \% .^{17}$

Haemoglobin, erythrocyte sedimentation rate, differential white cell count, and $C$ reactive protein (CRP) were assessed by automated counters, latex agglutination, and flow cytometry using standard techniques.

\section{BONE SCINTIGRAPHY}

Patients were scanned one day before and two days after treatment. On both occasions, patients were injected with $800-1000 \mathrm{MBq}$ of technetium-99m labelled methylene disphosphonate (Radpharm, Australia) with blood pool images taken two to four minutes after injection and delayed images taken three hours after injection. Palmar and dorsal views of the hands were obtained in both blood pool and delayed studies. Imaging was performed using a gammacamera with a small field of view connected to a dedicated nuclear medicine computer (GE Starcam, Milwaukee, WI, United States) with $256 \times 256$ matrix acquisition, low energy, all purpose collimator, and 10 minutes of acquisition time per image. All joints in each hand were scored on both blood pool and delayed studies by two nuclear medicine physicians. The scoring system was -1 for decreased joint activity, 0 for normal activity, and +1 for increased activity. Differences between observers were reviewed and a consensus decision was recorded

The scans were scored in random order by physicians who were unaware of whether they were pretreatment or posttreatment or which hand had received active treatment.

For statistical analysis, the changes in the treated hands were compared with the changes in the sham treated hands, using Wilcoxon sign rank tests. Correction for multiple measures indicated that a $p$ value of $<0.003$ was required for statistical significance.

\section{Results}

CLINICAL PARAMETERS

Eighteen of 25 patients (72\%) reported improvement in pain, but pain (as measured by the visual analogue scale) was reduced in both treated and sham treated hands after laser intervention ( $p<0.001$ for comparison before and after treatment). The figure shows the mean values for pain per week, where weeks 0 and 5 are assessment only. There was no difference in the extent of pain relief in the treated hands and the sham treated hands. To assess the patients's ability to discriminate between active laser and placebo they were 


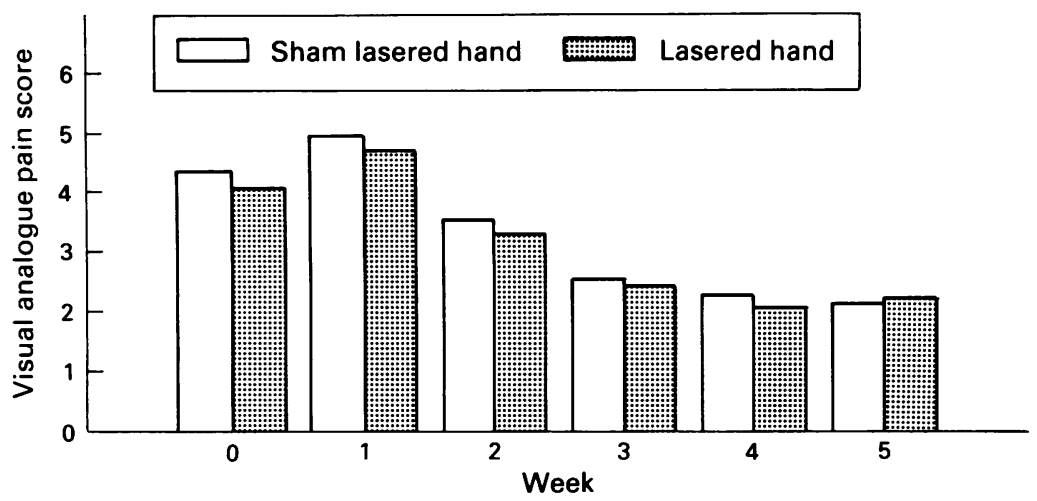

Each patient assessed pain in each hand separately using a visual analogue scale (VAS) from 0 to 10. The mean of these values is shown. Pain assessment fell in both the treated hand and in the sham treated hand. There was no difference between the degree of improvement in the two groups. designed this double blind trial to document any clinical or laboratory changes. We expected a strong placebo effect from the intensive contact with the therapist, combined with the 'high tech' appearance of the laser equipment, and we were therefore careful to ensure that both patient and therapist were ignorant of which treatment was being given.

The impressive change was the reduction in pain which was reported by $18 / 25(72 \%)$ subjects, but these changes were reported equally in both hands. Laboratory studies were unchanged making it unlikely that a systemic effect from laser treatment of one hand could have reduced pain in the other. Moreover, detailed function measures, including functional assessments of each hand, showed no changes in either the treated or sham treated hands, despite the reported reduction in pain. A placebo effect is clearly the most likely explanation for the reported analysis. Depending on the type of intervention, placebo responses varying from $6.2 \%$ to $80 \%$ have been described. ${ }^{20} 21$

Typically, uncontrolled studies of laser treatment in RA have claimed dramatic improvement with pain reduction of more than $90 \%$. One such paper conceded, however, that measures which were less placebo-sensitive, such as range of movement, 'did not always show rates of improvement similar to effectiveness of pain removal' ${ }^{4}$ At least four double blind trials have been previously published..$^{1-3} 22$ In each study a strong placebo effect was noted, with improvement in sham treated joints, usually in pain measurement, but sometimes in strength and range of movement.

Palmgren $e t \mathrm{al}^{3}$ used the same type of laser as in our study but the dose $\left(3.6 \mathrm{~J} / \mathrm{cm}^{2}\right)$ was slightly smaller. They showed significant improvements in grip strength, movement, joint swelling, and the duration of early morning stiffness compared with control patients who had sham treatment. Pain improved in both their patients' hands, but more so in their treated hands. Both erythrocyte sedimentation rate and total leucocyte counts fell with a significant trend. In Palmgren's study half the patients received active laser treatment and in half, placebo laser was used. We treated one hand and sham treated the other, and it is possible that, in our study, some systemic effect occurred that 'flowed over' from the actively treated to the placebo treated hand. Arguing against this possibility was the lack of change in erythrocyte sedimentation rate, or any other parameter measured. In addition, we found no change in any objective measurement or functional assessment. Despite the differences in design and dosage, it is difficult to reconcile our negative results with Palmgren's dramatic improvements.

Bliddal $e t a l^{1}$ and Goldman $e t a l^{2}$ used the same design as our study, but with different lasers. Bliddal's helium-neon laser produced a burning sensation in the actively treated joints of some patients, which would invalidate the blind element of the trial. Even so, less than half their patients reported pain relief, and there was no change in duration of early morning stiffness or joint range of movement. become. Previous published studies of the efficacy of laser treatment in RA have yielded conflicting results, ${ }^{1-3}$ and we therefore 
No changes in laboratory parameters were found. The authors concluded that laser treatment was of limited value.

Goldman's study used a Q-switch neodymium laser which delivers pulsatile irradiation at a fairly high output $\left(15 \mathrm{~J} / \mathrm{cm}^{2}\right.$ in $30 \mathrm{~ns}){ }^{2}$ All patients reported stinging from the laser, and more than $10 \%$ reported erythema or hyperpigmentation at the actively treated joints, invalidating efforts at making the trial blind. Both the treated and sham treated hands showed improvement for a range of measures: heat; erythema; pain; swelling; and tenderness. Erythema and pain were reported to have improved more in the treated hand than the placebo treated hand. Grasp and pinch strength were reported as more objective measures of improvement in the treated hands, but the probability values were not correctecd for multiple measures and were, in each case, $p=0.02$ and therefore unlikely to be significant. Similarly, the reported change in platelet aggregation $(p=0.025)$, which was proposed to indicate a systemic effect, would not be significant if the rate for each experiment were considered.

Walker et $a l^{22}$ reported significant pain reductions only in the treated patients, but this required nine weeks of treatment. Conceivably our actively treated patients might have improved to a significant degree with more prolonged treatment.

Photochemical reactions, particularly in vitamin $\mathrm{D}$ metabolism, melanin, and in the retina, ${ }^{21}$ are well described and there seems to be no a priori reason why laser treatment could not exert an effect on one or more of the many pathways that lead to pain and inflammation in the arthritic hand. We found no objective benefit with the dose regimen we used, but cannot exclude the possibility of efficacy with another regimen. The gallium-aluminiumarsenate lasers are safe, and have been efficacious in at least one well controlled trial, ${ }^{3}$ and it therefore seems prudent to use such lasers in further trials. We have demonstrated the absolute necessity of placebo controls in low power laser treatment research.
1 Bliddal C, Hellesen P, Ditlevsen P, Asselberghs J, Lyager L. Soft-laser therapy of rheumatoid arthritis. Scand $f$ Rheumatol 1987; 16: 225-8.

2 Goldman J A, Chiapella J, Casey $\mathrm{H}$, et al. Laser therapy of rheumatoid arthritis. Lasers Surg Med 1980; 1: 93-101.

3 Palmgren N, Jensen G F, Kaae K, Windelin M, Colov H C. Low-powered laser therapy in rheumatoid arthritis. Lasers Med Sci 1989; 4: 193-6.

4 Asada K, Yutoni Y, Shimazu A. Diode laser therapy for rheumatoid arthritis. A clinical evaluation of 102 joints treated with low reactive-level laser therapy (LLLT). Laser Ther 1989; 1: 147-51.

5 Basford J, Sheffield C, Mair S, Ilstrup M. Low energy helium neon laser treatment of thumb osteoarthritis. Arch Phys Med Rehabil 1987; 68: 794-7.

6 Haker E, Lundeberg T. Laser treatment applied to acupuncture points in lateral humoral epicondylagia, a double blind study. Pain 1990; 44: 243-7.

7 Klein R, Eek B. Low energy laser treatment and exercise for low back pain: double-blind controlled trial. Arch Phys Med Rehabil 1990; 71: 34-7.

8 Lundeberg T, Haker E, Thomas M. Effect of laser versus placebo in tennis elbow. Scand $\mathcal{J}$ Rehabil Med 1987; 19: placebo

9 Waylonis G, Wilke S, O'Toole D, Waylonis D A, Waylonis D B. Chronic myofascial pain: management by low-output helium-neon laser therapy. Arch Phys Med Rehabil 1988; 69: 1017-20.

10 England S, Farrell A, Coppack J, Struthers G, Bacon P. Low power laser therapy of shoulder tendonitis. Scand $\mathcal{F}$ Rheumatol 1989; 18: 427-31.

11 Snyder-Mackler L, Barry A, Perkins A, Soucek M. Effects of helium-neon laser irradiation on skin resistance and pain in patients with trigger points in the neck and back. Pain 1989; 69: 336-41.

12 Bashford J R. Low energy laser therapy: controversies and new research findings. Lasers Surg Med 1989; 9: $1-5$.

13 Tiphlova O, Karu T. Role of primary photoacceptors in low power laser effects. Lasers Surg Med 1989; 9; 67-9.

14 Herman J H, Khosla R C. Nd:YAG laser modulation of synovial tissue metabolism. Clin Exp Rheumatol 1989; 7: 505-12

15 Agnes P, Maas F. An interim Australian version of the Jebsen test of hand function. Aust $\mathcal{F}$ Physiol 1982; 28: 23-9.

16 Jebsen $\mathrm{R} \mathrm{H}$, Taylor $\mathrm{N}$, Trieschmann $\mathrm{R} \mathrm{B}$, Trotter $M \mathrm{~J}$, Howard L A. An objective and standardised test of hand function. Arch Phys Med Rehabil 1969; 50: 311-9.

17 Hill J, Bird H A, Lawton C W, Wright V. The arthritis impact measurement scales: An anglicised version to assess the outcome of British patients with rheumatoid arthritis. Br f Rheumatol 1990; 29: 193-6.

18 O'Brien P C, Shampo M A. Statistical considerations for performing multiple tests in a single experiment. 2 . performing multiple tests in a single experiment. 2. 1988; 63: 816-20.

19 Baxter G D, Bell A J, Allen J M, Ravey J. Low level laser therapy: current clinical practice in Northern Ireland. Physiotherapy 1991; 77: 171-8.

20 Ernst E, Saradeth T, Resch K L. The powerful placebo. Lancet 1991; 337: 611 .

21 Paulus H E, Egger M J, Ward J R, Williams J. Cooperative systemic studies of rheumatic diseases group. Analysis of improvement in individual rheumatoid arthritis patients treated with disease modifying antirheumatic drugs, based on findings in patients treated with placebo. Arthritis Rheum 1990; 33: 477-84.

22 Walker J B, Akhanjee L K, Cooney M M, Goldstein J, Tamoyoshi S, Segal-Gidon F. Laser therapy for pain of rheumatoid arthritis. Clin F Pain 1987; 3: 54-9. 